Article

\title{
Are Sub-National Agreements for Carbon Abatement Effective?
}

\author{
Terrence W. Iverson *, Joanne C. Burgess and Edward B. Barbier $\mathbb{D}$ \\ Department of Economics, Colorado State University, Fort Collins, CO 80526, USA; \\ jo.barbier@colostate.edu (J.C.B.); Edward.Barbier@colostate.edu (E.B.B.) \\ * Correspondence: Terry.Iverson@colostate.edu
}

Received: 12 June 2020; Accepted: 9 July 2020; Published: 16 July 2020

\begin{abstract}
Although national commitments to the Paris Climate Accord have waned, carbon mitigation by sub-national entities is on the rise globally. We examine the effectiveness of sub-national jurisdictions (e.g., states, provinces, cities) in collectively enacting greenhouse gas abatement strategies. We develop a simple model to explore the conditions under which an agreement among sub-national jurisdictions within a country may lead to substantial carbon abatement relative to a national policy determined through majority rule. We find that, in the absence of a functional national policy response, a coordinated sub-national agreement can generate meaningful abatement. This could form an important stopgap measure in the absence of better alternatives.
\end{abstract}

Keywords: carbon abatement; climate change; climate policy; greenhouse gas emissions; Paris Climate Agreement; sub-national agreements

\section{Introduction}

The 2015 Paris Climate Change Agreement committed national governments to limit global temperature rise to $2{ }^{\circ} \mathrm{C}$, a target that requires substantial reductions in greenhouse gas (GHG) emissions by 2050. The accord did not require signatories to agree on how to implement these objectives. Instead, it allowed individual countries to set their own national targets, abatement policies, and timelines for emission reductions, all subject to five-year review. It is unlikely that the current Nationally Determined Contributions (NDCs) of the Paris Agreement will achieve the $2{ }^{\circ} \mathrm{C}$ goal, much less the more ambitious $1.5^{\circ} \mathrm{C}$ target emphasized by many participants in the agreement $[1,2]$.

Full implementation of the conditional and unconditional NDCs pledged so far will lead to emissions of $56 \mathrm{GtCO}_{2} \mathrm{e}$ in $\mathrm{GHG}$ in 2030 [2]. This leaves a shortfall of $15 \mathrm{GtCO}_{2} \mathrm{e}$ in emission reductions to meet the $2{ }^{\circ} \mathrm{C}$ target, and a gap of $32 \mathrm{GtCO}_{2} \mathrm{e}$ in $\mathrm{GHG}$ reductions for the $1.5^{\circ} \mathrm{C}$ goal [2]. In order to meet the $2{ }^{\circ} \mathrm{C}$ target, countries need to triple their current emission reduction efforts, and increase their efforts five-fold if they are to keep global warming within the $1.5{ }^{\circ} \mathrm{C}$ goal (UNEP 2019). With the United States withdrawing from the accord and other nations also reconsidering commitments, even the pledged emission reductions may not be met.

While nations are lagging behind in achieving GHG reductions, carbon mitigation by sub-national jurisdictions within countries, such as states, provinces, cities and local governments, appears to be on the rise globally. Sub-national agencies and non-state actors may play an important role in initiating critical change required to meet the long term goals of the Paris Agreement [2,3]. Many sub-national jurisdictions in Brazil, China, India, Indonesia, Japan, Mexico, Russia, South Africa, the United States, and the European Union have announced voluntary pledges and low-carbon strategies designed to advance the goals of the Paris Agreement [4]. For example, of the 61 carbon pricing initiatives implemented or scheduled for implementation across the globe in 2020, which cover $12 \mathrm{GtCO}_{2} \mathrm{e}$ (i.e., $22 \%$ of global GHG emissions), over half are by sub-national jurisdictions [5]. What is more, these 
jurisdictions are increasingly cooperating to form regional and international agreements to coordinate reduction strategies and boost abatement. For example, 32 cities across the globe, including Cape Town, London, Sydney, New York and Tokyo, have pledged carbon neutrality by 2050 as part of a Carbon Neutrality Coalition [2].

In the United States, Hsu et al. [4] find that full implementation of sub-national commitments could reduce emissions at least halfway (between 670 and $810 \mathrm{MtCO}_{2} \mathrm{e} /$ year in 2030) to what would be needed to meet the US original target under the Paris Agreement. Significantly, the authors find that if sub-national governments in the US cooperate on renewable energy and carbon abatement, they could significantly lower emissions further, by between 1080 and $2340 \mathrm{MtCO}_{2} \mathrm{e} /$ year in 2030 . Already, such agreements are starting to emerge. The Regional Greenhouse Gas Initiative (RGGI) is the first mandatory market-based program in the United States to reduce GHG emissions across several major jurisdictions. The RGGI is a cooperative effort among the states of Connecticut, Delaware, Maine, Maryland, Massachusetts, New Hampshire, New Jersey, New York, Rhode Island, and Vermont to cap and reduce $\mathrm{CO}_{2}$ emissions from the power sector. These northeast and mid-Atlantic states, along with the District of Columbia, are also forming the Transportation Climate Initiative (TCI), a regional transportation effort to coordinate investment in cleaner transportation and infrastructure, which will most likely be funded by pricing carbon emissions from transportation. Together, the two regional agreements are likely to enhance the GHG emission reductions in transport and power by all the participating sub-national jurisdictions [6].

As more and more sub-national jurisdictions engage in carbon abatement through voluntary agreements and coordinated strategies, it raises an important question: Can such sub-national agreements (SNAs) be an effective replacement, in the absence of a credible national climate mitigation policy? To our knowledge, this is the first paper to explore this issue.

We develop a simple model to explore the conditions under which an agreement among sub-national jurisdictions within a country can lead to greater aggregate carbon abatement than a national climate policy determined through majority rule. The model shows that a coordinated sub-national agreement can generate meaningful abatement. This could form an important stopgap measure when national policy is lacking. The potential for a SNA to play a meaningful role in climate policy is even greater if society is polarized, where public opinion is divided between people who place a high value on climate action and those who do not value it at all. Under these conditions, there is the potential for SNAs to lead to a higher level of carbon abatement than under a national climate mitigation policy. The implications of our analysis are especially relevant for countries like the United States, where the federal government has renounced any national policy, public opinion on climate is divided, and sub-national jurisdictions that place a high value on climate action are pursuing agreements to abate carbon collectively.

The outline of our paper is as follows. We first develop our basic model that compares national climate policy consisting of a mandatory abatement target for all jurisdiction to an agreement on carbon abatement by sub-national jurisdictions. The model assumes uniform distribution of jurisdictions, which requires a SNA containing a minimum participation clause. Under the minimum participation clause the agreement will not go into effect unless all targeted jurisdictions participate. Next, we introduce polarization that divides jurisdictions into those placing a high value on climate action and those who don't value it at all. In this case, the target jurisdictions for the SNA is the set of high-valuation jurisdictions. As we discuss in the paper, one of the implications of a polarized distribution could be that there is no agreement on a national policy. Under these conditions, any SNA formed by the higher valued jurisdictions always generates more abatement. We conclude by discussing future research questions raised by this paper.

\section{Model}

Consider a country consisting of a number of jurisdictions. These jurisdictions differ in terms of their valuation of climate policy. The valuation parameter for climate policy in jurisdiction $i$ is $v_{i}$. 
The valuation parameter of jurisdiction $v_{i}$ is assumed to lie between zero and one. We assume that the country is subdivided into a unit continuum of heterogeneous jurisdictions, indexed $i$ in $[0,1]$. Jurisdictions differ in the extent to which they value aggregate (national) carbon abatement. Specifically, if aggregate abatement is $A$, the utility benefit for jurisdiction $i$ is $v_{i} A$.

On the cost side, abatement costs are quadratic in local abatement. If jurisdiction $i$ abates $a_{i}$, its abatement costs are $c a_{i}^{2}$. Each jurisdiction seeks to maximize net benefits.

Aggregate abatement is determined by the combined abatement of all jurisdictions. Given a specified abatement level for each jurisdiction, $\left[a_{i}\right]_{i \in[0,1]}$, aggregate abatement is

$$
A=\int_{0}^{1} a_{i} \text { di. }
$$

We further assume that sub-national carbon abatement (that is, abatement that is not part of a national policy) leads to leakage across jurisdictional boundaries at the constant leakage rate $L$, while no leakage occurs under national policy.

Our goal is to study how aggregate abatement compares under national policy with aggregate abatement in a sub-national agreement. We study this comparison under two different assumptions on the distribution of jurisdiction types. First, we consider the case in which the valuation parameter is uniformly distributed on the unit interval. Next, we consider a polarized situation in which jurisdictions either value climate policy fully $\left(v_{i}=1\right)$ or not at all $\left(v_{i}=0\right)$.

\section{Uniform Distribution of Types}

\subsection{National Policy}

National climate policy consists of a mandatory abatement target for all jurisdictions. If the target is $a_{N}$, then aggregate abatement is

$$
A=\int_{0}^{1} a_{N} \mathrm{di}=a_{N} .
$$

National policy is determined by majority rule, and each jurisdiction carries equal weight in the voting process. Given a candidate national abatement target $a_{N}$, net benefits for jurisdiction $i$ are $i a_{N}-c a_{N}^{2}$, which is strictly concave in $a_{N}$. It follows that the conditions for the Median Voter Theorem are satisfied, so the majority-rule policy will be determined by the preferences of the median jurisdiction. The Median Voter Theorem requires that preferences over one-dimensional alternatives are single-peaked. Concavity of net benefits in national policy ensures this.

With the valuation parameter uniformly distributed on the unit interval, the median jurisdiction has $v_{i}=0.5$. It follows that the most-preferred policy of the median jurisdiction solves

$$
\max _{a_{N}}\left[(0.5) a_{N}-c a_{N}^{2}\right]
$$

so national policy is $a_{N}=\frac{1}{4 c}$. Intuitively, abatement decreases in the cost of abatement.

\subsection{Sub-National Agreement}

Under the assumptions of the model, jurisdictions have no incentive to abate carbon unilaterally because they are too small to impact aggregate emissions. Nevertheless, they could impact aggregate emissions if they participate in a sub-national agreement that contains a minimum participation clause whereby the agreement will not go into affect unless all targeted jurisdictions participate. We study agreements of this form.

Specifically, we define a Sub-National Agreement (SNA) as an abatement target $\hat{a}$ that all participating jurisdictions must oblige, together with a set of target participants. Since the value of the climate policy is increasing in $v_{i}$, we formulate the set of target participants as a threshold $\hat{v}$ 
such that all $v_{i} \geq \hat{v}$ are expected to participate. Aggregate abatement under such an agreement is $(1-\hat{v})(1-L) \hat{a}$.

For each $\hat{a}$, we study the largest feasible SNA. To do this, we set $\hat{v}$ equal to the jurisdiction for which participation in agreement $(\hat{a}, \hat{v})$ produces net benefits of zero. Net benefits are strictly positive for all other participating jurisdictions. $\hat{v}$ solves

$$
\hat{v}[1-\hat{v}(\hat{a})](1-L) \hat{a}=c \hat{a}^{2},
$$

which is equivalent to

$$
\hat{v}^{2}-\hat{v}=-\frac{c \hat{a}}{1-L}
$$

Plotting both sides of this equation as a function of $\hat{v}$, one can see that there will only be an agreement if and only if

$$
\hat{a} \leq \frac{1-L}{4 c} .
$$

In the interest of studying the most optimistic version of an SNA, we consider the case in which abatement is as high as possible, thus where the constraint holds with equality. Thus,

$$
\hat{a}=\frac{1-L}{4 c} .
$$

It then follows that $\hat{v}(\hat{a})=0.5$, so national abatement is

$$
\begin{aligned}
a_{N}(\hat{a}) & =[1-\hat{v}(\hat{a})](1-L) \hat{a} \\
& =(1 / 2)(1-L) \frac{1-L}{4 c} \\
& =\frac{(1-L)^{2}}{8 c} .
\end{aligned}
$$

In this model, we allow for carbon leakage to occur. Carbon leakage refers to the situation where a region chooses to decrease its own carbon emissions as a result of an increase in emissions reduction by a second region with strict climate policy. In the best-case scenario with zero leakage, national abatement with the SNA generates aggregate abatement of $\frac{1}{8 c}$. This is half the abatement level achieved by the national agreement. The comparison becomes less favorable when carbon leakage is positive. Indeed, aggregate abatement with the SNA decreases with the square of leakage-adjusted abatement, so potential carbon leakage associated with sub-national efforts are an important concern.

\section{Polarized Distribution of Types}

Next, suppose that society is divided between people who place a high value on climate action and those who don't value it at all. Specifically, fraction $\theta$ of jurisdictions have $v_{i}=1$, while fraction $1-\theta$ have $v_{i}=0$.

\subsection{National Policy}

In this setting, the median voter has a valuation parameter equal to zero when $\theta \leq 0.5$ and a valuation parameter equal to one otherwise. The results in the case of national policy with $\theta \leq 0.5$ are straight forward, that is the policy is zero aggregate carbon abatement. This can be viewed as normalization and enables easy comparison with other sub-national policy cases, as shown in Figure 1.

When the median jurisdiction has $v=1$, its most-preferred policy solves

$$
\max _{a_{N}}\left[a_{N}-c a_{N}^{2}\right]
$$


so national policy is $a_{N}=\frac{1}{2 c}$. It follows that

$$
a_{N}= \begin{cases}\frac{1}{2 c}, & \text { if } \theta \geq 0.5 \\ 0, & \text { otherwise }\end{cases}
$$

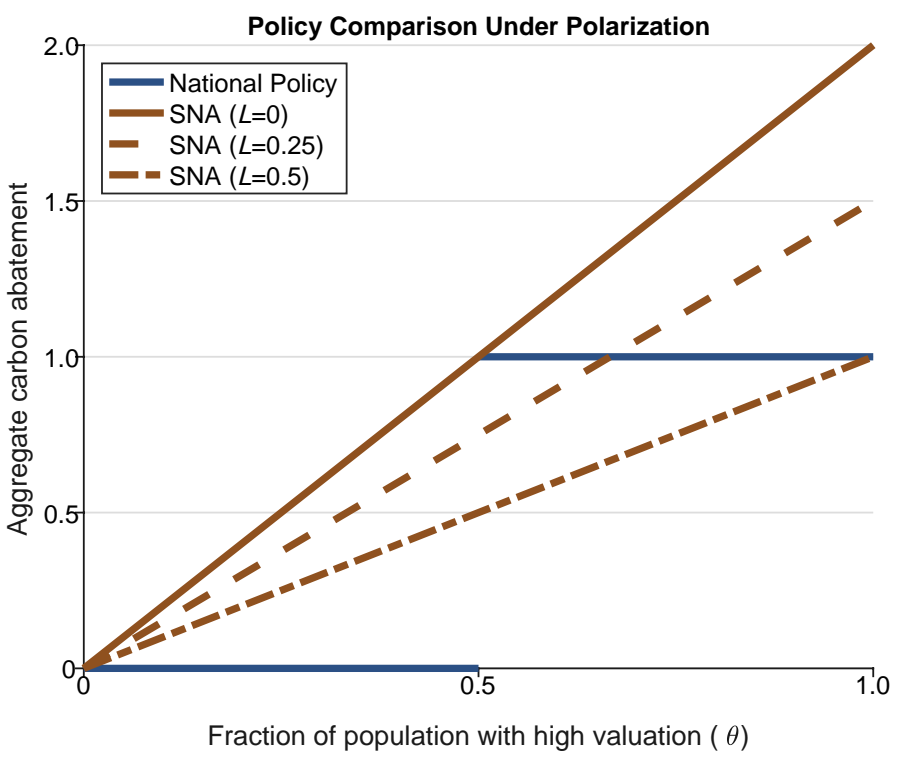

Figure 1. The figure compares aggregate abatement under national policy with aggregate abatement with a sub-national agreement (SNA) (for three assumptions about the leakage rate $L$ ). For each scenario, national abatement is plotted as a function of the fraction of the population with valuation $v_{i}=1$.

\subsection{Sub-National Policy}

In the sub-national setting, the target jurisdictions for the SNA is the set of high-valuation jurisdictions. The marginal participation condition in this case becomes

$$
\theta(1-L) \hat{a}=c \hat{a}^{2} .
$$

Thus,

$$
\hat{a}=\frac{\theta(1-L)}{c} .
$$

The plot in Figure 1 compares abatement under each policy, viewed as a function of the parameter $\theta$.

\subsection{Comparison and Discussion}

In the model with a uniform distribution of types, a SNA could achieve at best half the level of abatement achieved by the national policy. With leakage, a SNA would achieve less than half the level of abatement achieved by the national policy. In contrast, in the case of a polarized society, a SNA may potentially generate higher levels of abatement than under national policy, even in the presence of leakage. Figure 1 shows how to aggregate abatement compares in the national-policy setting with the SNA setting under a polarized society. The potential for a SNA to generate promising policy outcomes is much greater in the case of polarization. We do not provide an analogous plot for the uniform distribution case because the policies, in that case, can be easily imagined from the analytical results. Indeed, when leakage is zero, national abatement with a SNA is always greater than national abatement with national policy. With higher levels of leakage ( $L=0.25$ and and $L=0.5$ in the figure) the achieved level of aggregate abatement is lower. Nevertheless, aggregate abatement remains higher 
under a SNA than with national policy for a broad set of the parameter space, including the interval for which less than half the population have a high valuation of climate action, i.e., $\theta<0.5$.

To better understand the comparison, let's first consider the case in which the fraction of the population with a high valuation of climate action is under $50 \%$, that is $\theta<0.5$. In this case, the national policy is chosen by the median voter who has $v_{1}=0$. As a result, aggregate abatement is zero since the median voter case does not value climate action and prefers zero abatement. In contrast, the SNA induces all participating jurisdictions who place a high value on climate action to abate. The aggregate amount of abatement under the SNA rises in the fraction $\theta$ and is always positive and thus higher than the zero abatement achieved under the national policy. When leakage is zero ( $L=0$ in Figure 1$)$, the SNA achieves the highest level of aggregate carbon abatement. When leakage is positive, $(L=0.25$ and $L=0.5$ ) the achieved level of aggregate abatement by a SNA is lower than in the case where the leakage is zero. However, aggregate abatement still remains higher under a SNA than the zero abatement policy determined nationally, when less than half the population has a high valuation of climate action, i.e., $\theta<0.5$.

When the fraction of the population with a high valuation of climate action is over $50 \%$, that is $\theta>0.5$, it is less obvious why aggregate abatement remains higher in the SNA case that it does under the national policy. Let us first look at the national policy scenario. In this case, the aggregate amount of carbon abatement is chosen by a median voter with $v_{i}=1$. This person chooses carbon abatement policy to maximize net benefits on climate action. In contrast in the SNA scenario, given the assumptions of the model, the SNA rallies the marginal participating jurisdiction to the brink of its participation constraint. Since all participating counties have the same valuation parameter, $v_{1}=1$, all jurisdictions are marginal in this sense. Therefore, they are all united to undertake carbon abatement to the edge of their participation constraint, which is the point at which their net benefits on climate action are zero. So under these conditions, the SNA case leads to a much higher level of aggregate carbon emissions (i.e., net benefits on climate action are zero) compared to the national policy case (i.e., net benefits on carbon action are maximized).

In the case where $\theta>0.5$ and leakage is zero $(L=0)$, the SNA always leads to greater carbon abatement than under the national policy. The presence of leakage reduces the aggregate carbon abatement under a SNA. However, when there is a combination of a low level of leakage (e.g., $L=0.25$ ) and a sizable proportion of the population has a high valuation of climate action (e.g., $\theta<0.75$ ), then the SNA leads to a higher level of aggregate carbon abatement than that undertaken by national policy. When leakage is very high (e.g., $L=0.5$ ) then the benefits of the SNA are reduced and national policy provides the highest level of aggregate carbon abatement.

There are several situations where the level of abatement under the SNA corresponds to the national policy outcome, as shown in Figure 1. For example, in the case where exactly half the population have a high valuation of climate action, (i.e., $\theta=0.5$ ) and there is no leakage (i.e., $L=0$ ), then the aggregate level of carbon abatement of the SNA equals that of the national policy based on the median voter. As the figure shows, there are other outcomes where the level of abatement under the SNA with leakage also corresponds to the national policy outcome, depending on a combination of the faction of the population with a high valuation and the extent of leakage.

In summary, when there is a uniform distribution of types in society, a national policy always leads to a higher level of aggregate abatement compared to a SNA. At most, the SNA can achieve half the level of abatement undertaken by the national agreement. The presence of leakage reduces the level of SNA abatement further. In contrast, when there is a polarized society, a SNA may generate higher levels of abatement than that achieved under a national agreement under a number of scenarios. For example, the SNA leads to higher levels of aggregate carbon abatement when the fraction of the population with a high valuation of climate action is under $50 \%$, when the fraction of the population with a high valuation of climate action is over $50 \%$ and there is zero leakage, and when the fraction of the population with a high valuation of climate action is over $50 \%$ and there is a low level of leakage combined with a substantial proportion of the population having a high valuation of climate action. 


\section{Conclusions}

This paper has developed a simple model to explore conditions under which an agreement among sub-national jurisdictions within a country may lead to more aggregate carbon abatement than a national climate policy determined through majority rule. The model shows that a coordinated SNA can generate significant abatement, and can provide an important stopgap measure in the absence of national policy.

While the model developed in this paper is simple, it captures an essential feature of a complex situation. The issue of sub-national agreements is critical for climate change policy analysis but has not been analyzed in this way previously. Therefore, the paper makes a unique and important contribution to the existing literature on carbon abatement and can serve as inspiration for further economic analysis of questions related to sub-national climate policy. The results of the analysis developed in this paper are economically interesting, and are particularly helpful in explaining the possible outcomes in the US context, where the current political climate has led to polarization. Furthermore, it can also be applied to countries within the European Union or globally where similar polarization is occurring.

The contribution of a SNA is particularly important when society is polarized between two extremes and public opinion is divided between people who place a high value on climate action and those who don't value it at all. For example, a recent study by Hall et al. [7] looked at climate change beliefs, pro-environmental behavior, and other climate-change related measures of American adults. This study determined three distinct clusters of Americans: the "skeptics" who believed least in climate change; the "cautiously worried" who had moderate beliefs in climate change; and, the "highly concerned" who had the strongest beliefs and concern about climate change. Attitudes towards government climate policies and individual-level pro-environmental actions varied considerably across these groups [7]. This can result in a divided public opinion at the national level about climate action, and polarization for and against policies for climate abatement. Under these conditions, sub-national jurisdictions may take action to compensate for the lack of political will and climate policy at the national level $[8,9]$. When this occurs, the SNA can lead to a higher level of carbon abatement than that achieved under a national climate mitigation policy.

The implications of our analysis are especially relevant for countries such as the United States, where the federal government has renounced any national policy, public opinion on climate remains divided, and sub-national jurisdictions that place a high value on climate action are pursuing agreements to abate carbon collectively. Even though progress at the national level has been slow [10], at the sub-national level there has been significant unilateral and coordinated action [3,11-13]. Full implementation of the existing sub-national commitments in the US could achieve at least half of the carbon emission reductions needed to meet its original target under the Paris Agreement [4].

However, there are numerous factors that can restrict the implementation of carbon abatement policies by sub-national entities, such as opposition from powerful industrial sectors and constraints imposed by national governments and regional agreements. Real-world implementation of carbon abatement policies can, therefore, fall short of the preferred policies of sub-national entities [14]. As noted by [15], there has been a sizeable gap between policy commitments and actual carbon abatement implementation at both the national and sub-national levels. Roelfsema et al. [15] show that if Nationally Determined Contributions (NDCs) pledged under the Paris Climate Change Agreement were fully implemented, the gap between current policies and the Paris goals would be reduced by as much as a third. The gap between current policies and pledges and targets at the global and country-level is recorded by Climate Action Tracker: https://climateactiontracker.org/global/catemissions-gaps/.

Although the SNA may produce an environmentally effective outcome, whether this can be considered "better" than the alternative national policy option needs to take into account several other considerations. For example, the polarized SNA may lead to more emissions abatement overall, but this level of abatement may be non-optimal in terms of an economically efficient outcome. That is, the SNA rallies jurisdictions to abate their carbon emission up until the point where their net benefits 
on climate action are zero, compared to the economically efficient national policy outcome where the net benefits on carbon action are maximized. However, small-scale decentralized policy action may have the advantage of leading to more policy innovation and the ability to adapt to new situations with more flexibility than at the national level $[3,16]$. Sub-national authorities may also be better placed to manage local climate challenges, such as flood risk, water stress and urban infrastructure design and development [17].

An additional concern of the polarized SNA case is that it may lead to an unequal sharing of the costs and benefits of climate action. Those jurisdictions within the SNA bear an excessive burden of costs of implementing abatement whilst those outside the group receive the benefits of averted climate change as free-riders. A coordinated national policy that includes all jurisdictions may also provide greater opportunities for minimizing the costs of abating carbon rather than one within a limited number of jurisdictions. Finally, there is also the possibility that the SNA can add to the problem of polarization, especially when leakage outside the SNA occurs and contributes to divisions across sub-national jurisdictions.

Even though there are several disadvantages associated with SNAs, their potential to provide a critical stop-gap opportunity in the absence of national policy needs urgent recognition. The 2015 Paris Climate Change Agreement committed national governments to limiting global warming and substantially reducing greenhouse gas (GHG) emissions by 2050. In order to meet the $2{ }^{\circ} \mathrm{C}$ target, countries need to triple their current emission reduction efforts, and increase their efforts five-fold, if they are to keep global warming within the $1.5^{\circ} \mathrm{C}$ goal (UNEP 2019). In this paper, we have shown how SNAs can make an important contribution to this objective.

Author Contributions: Conceptualization, T.W.I., J.C.B. and E.B.B.; methodology, T.W.I. with input from J.C.B. and E.B.B.; software, not applicable; validation, T.W.I. with input from J.C.B. and E.B.B.; formal analysis, T.W.I. with input from J.C.B. and E.B.B.; investigation, T.W.I., J.C.B. and E.B.B.; resources, T.W.I., J.C.B. and E.B.B.; data curation, not applicable; writing—original draft preparation, T.W.I., J.C.B. and E.B.B.; writing—review and editing, T.W.I., J.C.B. and E.B.B.; visualization, T.W.I., J.C.B. and E.B.B.; supervision, not applicable; project administration, not applicable; funding acquisition, not applicable. All authors have read and agreed to the published version of the manuscript.

Funding: This research received no external funding.

Conflicts of Interest: The authors declare no conflict of interest.

\section{References}

1. Nordhaus, W. Projections and uncertainties about climate change in an era of minimal climate policies. Am. Econ. J. Econ. Policy 2018, 10, 333-360. [CrossRef]

2. Emissions Gap Report 2019; United Nations Environment Program, UNEP: Nairobi, Kenya, 2019.

3. Somanathan, E.; Sterner, T.; Sugiyama, T.; Chimanikire, D.; Dubash, N.K.; Essandoh-Yeddu, J.; Fifita, S.; Goulder, L.; Jaffe, A.; Labandeira, X.; et al. National and Sub-National Policies and Institutions Climate Change 2014: Mitigation of Climate Change; Contribution of Working Group III to the Fifth Assessment Report of the Intergovernmental Panel on Climate Change; Edenhofer, O.R., Ed.; Cambridge University Press: Cambridge, UK; New York, NY, USA, 2014; pp. 1141-1205.

4. Hsu, A.; Weinfurter, A.; Feierman, A.; Xie, Y.; Yeo, Z.Y.; Lütkehermöller, K.; Kuramochi, T.; Lui, S.; Höhne, N.; Roelfsema, M. Global Climate Action of Regions, States and Businesses; Research Report; Data Driven Yale, New Climate Institute, PBL Netherlands Environmental Assessment Agency: The Hague, The Netherlands, 2018. Available online: http:/ / bit.ly/yale-nci-pbl-global-climate-action (accessed on 15 June 2020).

5. State and Trends of Carbon Pricing; World Bank: Washington, DC, USA, 2020.

6. Burtraw, D.; Domeshek, M. Interactions of Transportation Carbon Pricing with the Electricity Market in the TCI Region; Resources for the Future Issue Briefing 20-04; Resources for the Future: Washington, DC, USA, 2020.

7. Hall, M.P.; Lewis, N.A., Jr.; Ellsworth, P.C. Believing in climate change, but not behaving sustainably: Evidence from a one-year longitudinal study. J. Environ. Psychol. 2018, 56, 55-62. [CrossRef] 
8. Schreurs, M.A. From the bottom up: Local and subnational climate change politics. J. Environ. Dev. 2008, 17, 343-355. [CrossRef]

9. Dubash, N.K. From norm taker to norm maker? Indian energy governance in global context. Glob. Policy 2011, 2, 66-79. [CrossRef]

10. Mehling, M.; Frenkil, D.J. Climate law in the united states: Facing structural and procedural limitations. In Climate Change and the Law; Springer: Cham, Switzerland, 2013; pp. 473-487.

11. Rabe, B.G. Second-generation climate policies in the states: Proliferation, diffusion, and regionalization. In Changing Climates in North American Politics: Institutions, Policymaking, and Multilevel Governance; MIT Press: Cambridge, MA, USA, 2009; pp. 67-86.

12. Rabe, B.G. Greenhouse Governance: Addressing Climate Change in America; Brookings Institution Press: Washington, DC, USA, 2010.

13. Posner, P.L. The politics of vertical diffusion: The states and climate change. In Greenhouse Governance: Addressing Climate Change in America; Brookings Institution Press: Washington, DC, USA, 2010; pp. 73-98.

14. Jenkins, J.D. Political economy constraints on carbon pricing policies: What are the implications for economic efficiency, environmental efficacy, and climate policy design? Energy Policy 2014, 69, 467-477. [CrossRef]

15. Roelfsema, M.; van Soest, H.L.; Harmsen, M.; van Vuuren, D.P.; Bertram, C.; den Elzen, M.; Höhne, N.; Iacobuta, G.; Krey, V.; Kriegler, E.; et al. Taking stock of national climate policies to evaluate implementation of the paris agreement. Nat. Commun. 2020, 11, 1-12. [CrossRef] [PubMed]

16. Galarraga, I.; Gonzalez-Eguino, M.; Markandya, A. The role of regional governments in climate change policy. Environ. Policy Govern. 2011, 21, 164-182. [CrossRef]

17. Corfee-Morlot, J.; Kamal-Chaoui, L.; Donovan, M.G.; Cochran, I.; Robert, A.; Teasdale, P.-J. Cities, Climate Change and Multilevel Governance; OECD Environmental Working Papers 14; OECD: Paris, France, 2009.

(C) 2020 by the authors. Licensee MDPI, Basel, Switzerland. This article is an open access article distributed under the terms and conditions of the Creative Commons Attribution (CC BY) license (http:/ / creativecommons.org/licenses/by/4.0/). 